Case Reports in
Gastroenterology
Case Rep Gastroenterol 2020;14:561-569

DOI: 10.1159/000510920

Published online: October 30, 2020

(C) 2020 The Author(s)

Published by S. Karger AG, Basel

www.karger.com/crg

This article is licensed under the Creative Commons Attribution-NonCommercial 4.0 International License (CC BY-NC) (http://www.karger.com/Services/OpenAccessLicense). Usage and distribution for commercial purposes requires written permission.

\title{
Cronkhite-Canada Syndrome Successfully Treated by Corticosteroids before Presenting Typical Ectodermal Symptoms
}

\author{
Kazumoto Murata ${ }^{a, b} \quad K_{i i c h i}$ Sato $^{b}$ Shinya Okadac Daisuke Suto $^{b}$ \\ Takaaki Otake $^{b}$ Yutaka Kohgo ${ }^{\text {b }}$ \\ aDivision of Virology, Department of Infection and Immunity, Jichi Medical University \\ School of Medicine, Shimotsuke, Japan; ${ }^{b}$ Department of Gastroenterology, International \\ University of Health and Welfare, Nasushiobara, Japan; 'Department of Pathology, \\ International University of Health and Welfare, Nasushiobara, Japan
}

\section{Keywords}

Cronkhite-Canada syndrome $\cdot$ Corticosteroids $\cdot$ Nonhereditary polyposis $\cdot$ Remission

\begin{abstract}
Cronkhite-Canada syndrome (CCS) is a rare disease characterized by diffuse gastrointestinal polyposis with chronic diarrhea and ectodermal change, but its etiology is unknown. We present a case at the age of 26 years complaining of epigastralgia and weight loss. Endoscopic examination revealed extensive diffuse polypoid lesions of the stomach and the terminal ileum, all of which showed hyperplastic polyps pathologically. There were no polypoid lesions in his colon. He has no family history of diffuse gastrointestinal polyposis. Diffuse gastrointestinal hyperplastic polyposis without any hereditary association led us to suspect this case as CCS although he did not show chronic diarrhea and any ectodermal symptoms such as onychodystrophy, alopecia, and hyperpigmentation. After initiation of a corticosteroid therapy, his epigastralgia disappeared and he gained appetite and weight, accompanied by normalization
\end{abstract}




\section{Case Reports in Gastroenterology}

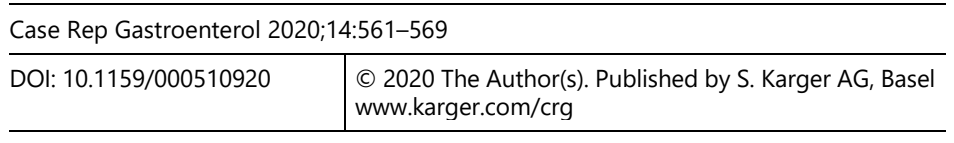

Murata et al.: Cronkhite-Canada Syndrome before Presenting Ectodermal Symptoms

of serum albumin levels. Endoscopic examination 1 year after initiation of corticosteroid therapy revealed a decrease in the number of gastric polyposis and those inflammations. This rare young case may suggest that early therapeutic intervention with corticosteroids could improve the prognosis of CCS, preventing not only malnutrition but also appearance of several ectodermal symptoms.

(c) 2020 The Author(s)

Published by S. Karger AG, Basel

\section{Introduction}

Cronkhite-Canada syndrome (CCS) is a rare nonhereditary disease characterized by diffuse gastrointestinal hyperplastic polypoid lesions and ectodermal symptoms such as pigmentation, alopecia and onychatrophia. Since Cronkhite and Canada [1] first reported about this syndrome in 1955, more than 500 cases have been reported worldwide, the majority of which were from Japan [2]. The etiology of CCS is currently unknown, and the association between gastrointestinal polyposis and ectodermal symptoms is undetermined.

We here report a rare young case of diffuse gastrointestinal polyposis without any ectodermal symptoms who was successfully treated by corticosteroids.

\section{Case Presentation}

A 26-year-old Japanese male who had presented epigastralgia for 10 months visited our hospital. He had lost about $6 \mathrm{~kg}$ because of his poor appetite. He did not complain of fever, cough, and chronic diarrhea. He had a proton pump inhibitor for those symptoms from a doctor nearby, but no improvement was observed. On physical examination, his height and body weight were $153 \mathrm{~cm}$ and $42.0 \mathrm{~kg}$, respectively. He had mild epigastric tenderness, but no masses were palpable on his whole abdomen. No peripheral edema was observed. His nails were intact, and no pigmentation was found in his whole skin or mucous membranes. Alopecia was not observed. He did not have any relatives with polyposis in the gastrointestinal (GI) tracts. Blood examination showed negative Helicobacter pylori antibody, antinuclear antibody, and normal serum IgG4 levels.

Chest and abdominal X-rays were normal. The patient underwent esophago-gastro-duodenoscopy (EGDS), which revealed diffuse multiple sessile polypoid lesions in the whole stomach, but no polypoid lesions were seen in the esophagus or the duodenum (Fig. 1). Colonoscopy showed similar multiple polypoid lesions in the terminal ileum, but no such polypoid lesions were observed in the whole colon (Fig. 2). Pathology of the gastric polypoid lesions revealed hyperplastic mucosa, but focal dilated cystic glands were not seen (Fig. 3). The tissue biopsy from the terminal ileum showed similar findings (Fig. 4). He lacked chronic diarrhea and ectodermal abnormalities, which were seen in the typical CCS cases. No appropriate explanations of the diffuse gastrointestinal polyposis except for CCS were found, based on a combination of clinical, endoscopic and pathological findings. Therefore, we diagnosed him as having CCS.

The patient was treated with daily oral prednisolone, which was initially administered at a dose of $0.5 \mathrm{mg} / \mathrm{kg}$ with a proton pump inhibitor (vonoprazan fumarate: $20 \mathrm{mg}$ daily), 


\section{Case Reports in Gastroenterology}

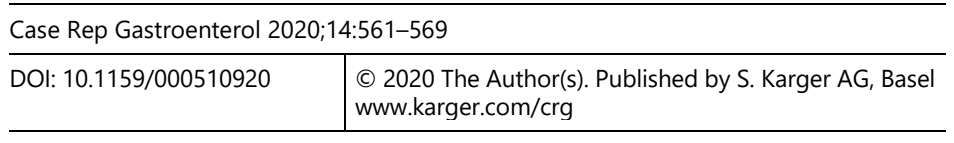

Murata et al.: Cronkhite-Canada Syndrome before Presenting Ectodermal Symptoms

following tapered prednisolone and continued at a daily dose of $5 \mathrm{mg}$. After initiation of corticosteroids, he gradually recovered his appetite and gained weight up to $5 \mathrm{~kg}$, accompanied by improved protein synthesis such as serum albumin, cholinesterase and total cholesterol levels (Table 1). EGDS 1 year after initiation of corticosteroid revealed that the size and the numbers of polypoid lesions had decreased, and the reddish lesions had changed to normal color (Fig. 5). During these observations, he had never experienced any chronic diarrhea or ectodermal symptoms.

\section{Discussion/Conclusion}

The common symptoms of CCS at initial diagnosis include chronic diarrhea (70.0\%), dysgeusia (64.8\%), onychodystrophy (64.4\%), alopecia (49.0\%), and hyperpigmentation (48.8\%) [2]. Protein-losing enteropathy is often observed in CCS because of polypoid lesions in the GI tracts. The mean age of initial diagnosis of CCS is between 50 and 60 years [3] and young patients have rarely been reported $[4,5]$.

The diagnosis of the current case of CCS is controversial because of a lack of chronic diarrhea or typical ectodermal symptoms. The case had multiple diffuse polypoid lesions whose pathology showed hyperplasia in the stomach and the intestine without any ectodermal changes. Therefore, differential diagnosis such as Peutz-Jeghers syndrome, juvenile polyposis and Cowden syndrome should be discussed [6]. However, these three diseases above were unlikely for the current case because he did not have any relatives with polyposis in the GI tracts.

Diffuse hyperplastic polypoid lesions of the stomach and terminal ileum in our case were not explained by any other diagnostic criteria. Initial symptoms of most patients with CCS are chronic intermittent diarrhea and malnutrition caused by protein-losing enteropathy, which could be one of the causes of death [7]. In other words, most patients with CCS have no or little symptoms for many years even though they have diffuse polypoid lesions in the GI tract because polypoid lesions may not suddenly appear. Typical CCS patients presented several ectodermal symptoms when initial diagnosis was made after experiencing long-term diarrhea. Alternatively, our case complained of epigastralgia as initial symptom, and incidentally uncovered his gastric polypoid lesions by EGDS. CCS is a rare nonhereditary disease, and the ectodermal changes are not associated with any gene disorders. In addition, ectodermal symptoms are sometimes reversible with immunosuppressive agents $[7,8]$. Therefore, it could be one of the plausible explanations that ectodermal changes in CCS generally occur due to malnutrition caused by protein-losing enteropathy. From these points of view, it is possible that the current case was found in the early phase of CCS before presenting chronic diarrhea and characteristic ectodermal symptoms.

The etiology of CCS is currently unknown. However, positive autoimmune markers such as anti-nuclear antibodies [9] and favorable responses for steroid [7] or cyclosporine [8] are consistent with an autoimmune mechanism underlying CCS. We treated the current case with corticosteroids, which decreased the size and the number of polypoid lesions in the stomach, as well as his nutritional status such as gained body weight and elevation of serum albumin levels. From these points of view, it is suggested that early diagnosis before presenting malnutrition could improve the prognosis and prevent the ectodermal changes in CCS. Moreover, 


\section{Case Reports in Gastroenterology}

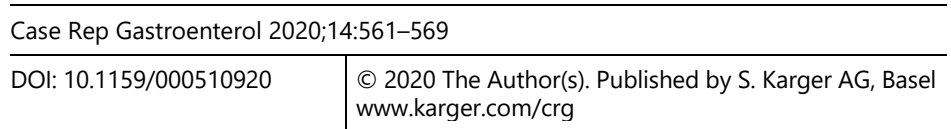

Murata et al.: Cronkhite-Canada Syndrome before Presenting Ectodermal Symptoms

the current case lacked polypoid lesions in the colon, which may be one of the reasons why the case did not experience malnutrition by protein-losing enteropathy. The reason why focal dilated cystic glands, which were often seen in typical CCS patients as pathological findings, were not found in our case was undetermined. It could be a plausible explanation that our case was found in the early phase of CCS before forming these findings.

The prevalence of gastric or colon cancer among Japanese patients with CCS was approximately $10-20 \%$, both of which were significantly higher than that in the general population [2]. However, achievement of sustained endoscopic remission could lead to decreased cancer risk [2]. The prognosis of CCS was reported to be poor with inanition, anemia, and anasarca before [10]. However, recent remarkable improvements of digestive and ectodermal disorder with various treatments including corticosteroid could improve the prognosis [7, 9].

Although there are controversial discussions in terms of the diagnosis, the current case may suggest that early diagnosis and the following therapies with corticosteroids could prevent malnutrition or characteristic ectodermal changes. This patient should be followed for long-term, and other reports like ours would be awaited.

\section{Statement of Ethics}

Written informed consent for publication of the clinical details and clinical images was obtained from the patient.

\section{Conflict of Interest Statement}

The authors have no conflicts of interest to disclose in association with this study.

\section{Funding Sources}

No funding was obtained for this study.

\section{Author Contributions}

K.M., K.S., S.O., D.S., T.O., and Y.K. carried out and confirmed the diagnosis, provided the details of the case and contributed to design of the report. K.M. drafted the manuscript. All authors read and approved the final version of the manuscript. 


\section{Case Reports in Gastroenterology}

\begin{tabular}{l|l}
\hline DOI: 10.1159/000510920 & $\begin{array}{l}\text { @ } 2020 \text { The Author(s). Published by S. Karger AG, Basel } \\
\text { www.karger.com/crg }\end{array}$
\end{tabular}

Murata et al.: Cronkhite-Canada Syndrome before Presenting Ectodermal Symptoms

\section{References}

1 Cronkhite LW Jr, Canada WJ. Generalized gastrointestinal polyposis; an unusual syndrome of polyposis, pigmentation, alopecia and onychotrophia. N Engl J Med. 1955 Jun;252(24):1011-5.

2 Watanabe C, Komoto S, Tomita K, Hokari R, Tanaka M, Hirata I, et al. Endoscopic and clinical evaluation of treatment and prognosis of Cronkhite-Canada syndrome: a Japanese nationwide survey. J Gastroenterol. 2016 Apr;51(4):327-36.

3 Ward EM, Wolfsen HC. Review article: the non-inherited gastrointestinal polyposis syndromes. Aliment Pharmacol Ther. 2002 Mar;16(3):333-42.

4 Faria MA, Basaglia B, Nogueira VQ, de Mendonca TB, Kaiser Junior RL, Filho IJ, et al. A case of adolescent Cronkhite-Canada syndrome. Gastroenterol Res. 2018 Feb;11(1):64-7.

5 Bandyopadhyay D, Hajra A, Ganesan V, Kar SS, Bhar D, Layek M, et al. Cronkhite-Canada syndrome: A rare cause of chronic diarrhea in a young man. Case Rep Med. 2016;2016:4210397.

6 Calva D, Howe JR. Hamartomatous polyposis syndromes. Surg Clin North Am. 2008 Aug;88(4):779-817.

7 Goto A. [Cronkhite-Canada syndrome: observations about treatment, course and prognosis of 123 cases reported in Japan]. Nihon Geka Hokan. 1988 Sep;57(5):427-33.

8 Yamakawa K, Yoshino T, Watanabe K, Kawano K, Kurita A, Matsuzaki N, et al. Effectiveness of cyclosporine as a treatment for steroid-resistant Cronkhite-Canada syndrome; two case reports. BMC Gastroenterol. 2016 Oct;16(1):123.

9 Wen XH, Wang L, Wang YX, Qian JM. Cronkhite-Canada syndrome: report of six cases and review of literature. World J Gastroenterol. 2014 Jun;20(23):7518-22.

10 Johnson GK, Soergel KH, Hensley GT, Dodds WJ, Hogan WJ. Cronkite-Canada syndrome: gastrointestinal pathophysiology and morphology. Gastroenterology. 1972 Jul;63(1):140-52. 


\section{Case Reports in Gastroenterology}

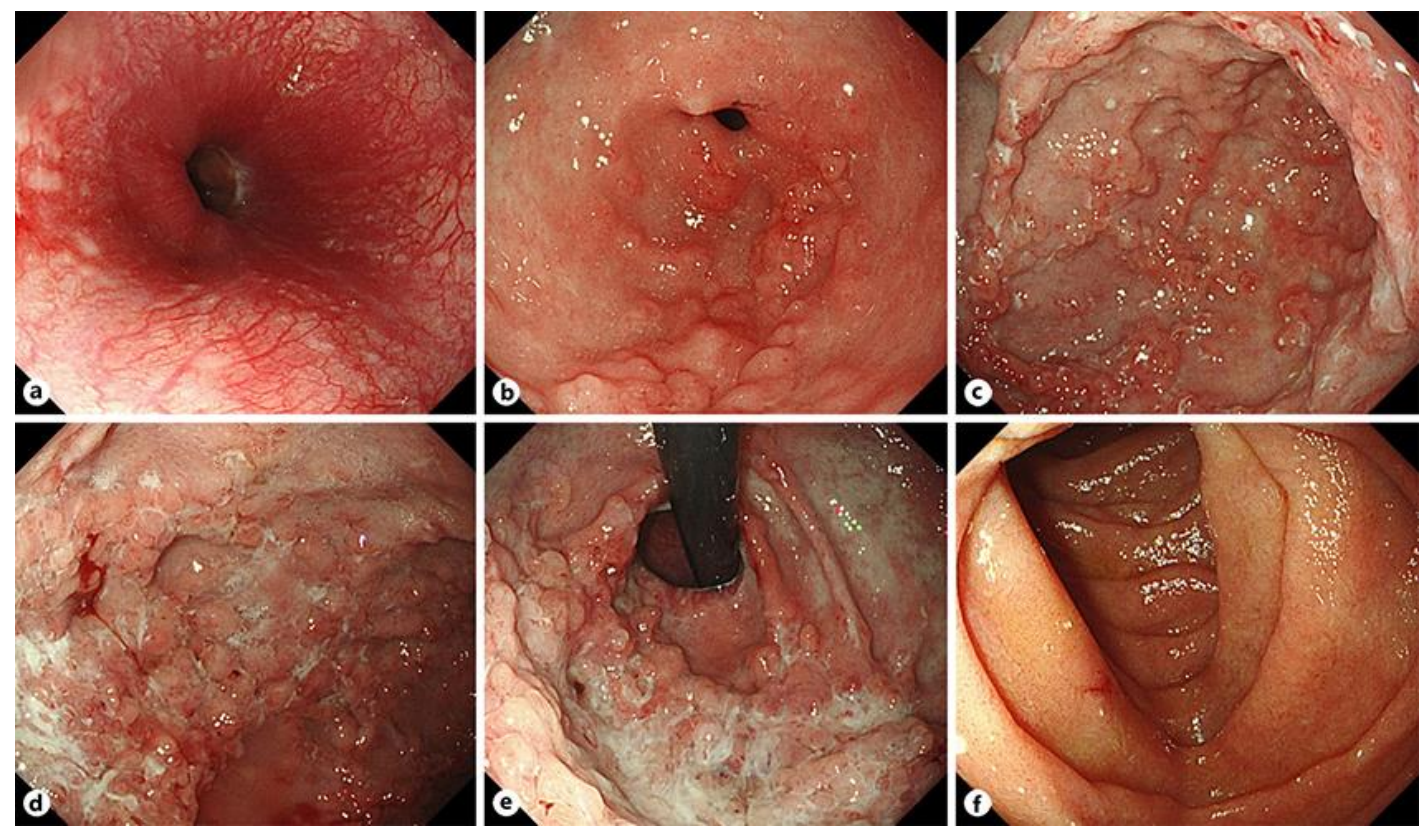

Fig. 1. Initial esophago-gastro-duodenoscopy. Diffuse sessile polypoid lesions in the stomach were seen (a: esophagus, b: antrum, c: great curvature, $\mathbf{d}$ : anterior wall of the upper part of stomach angle, e: cardia, and f: duodenum).
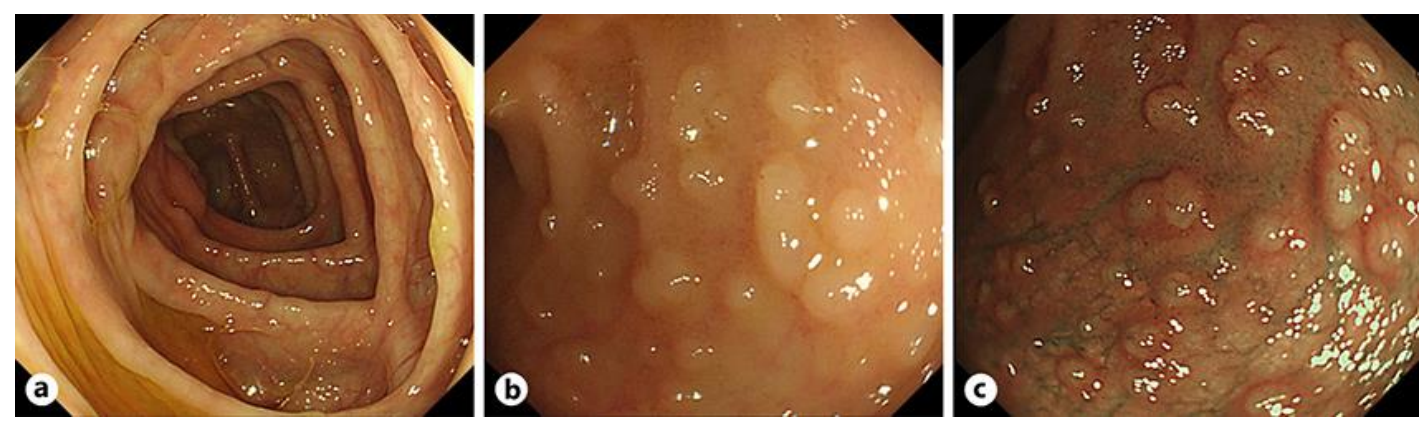

Fig. 2. Colonoscopy before treatment (a: transverse colon, b: terminal ileum, c: terminal ileum stained with indigo carmine). Polypoid lesions were observed only in the terminal ileum. 


\section{Case Reports in Gastroenterology}

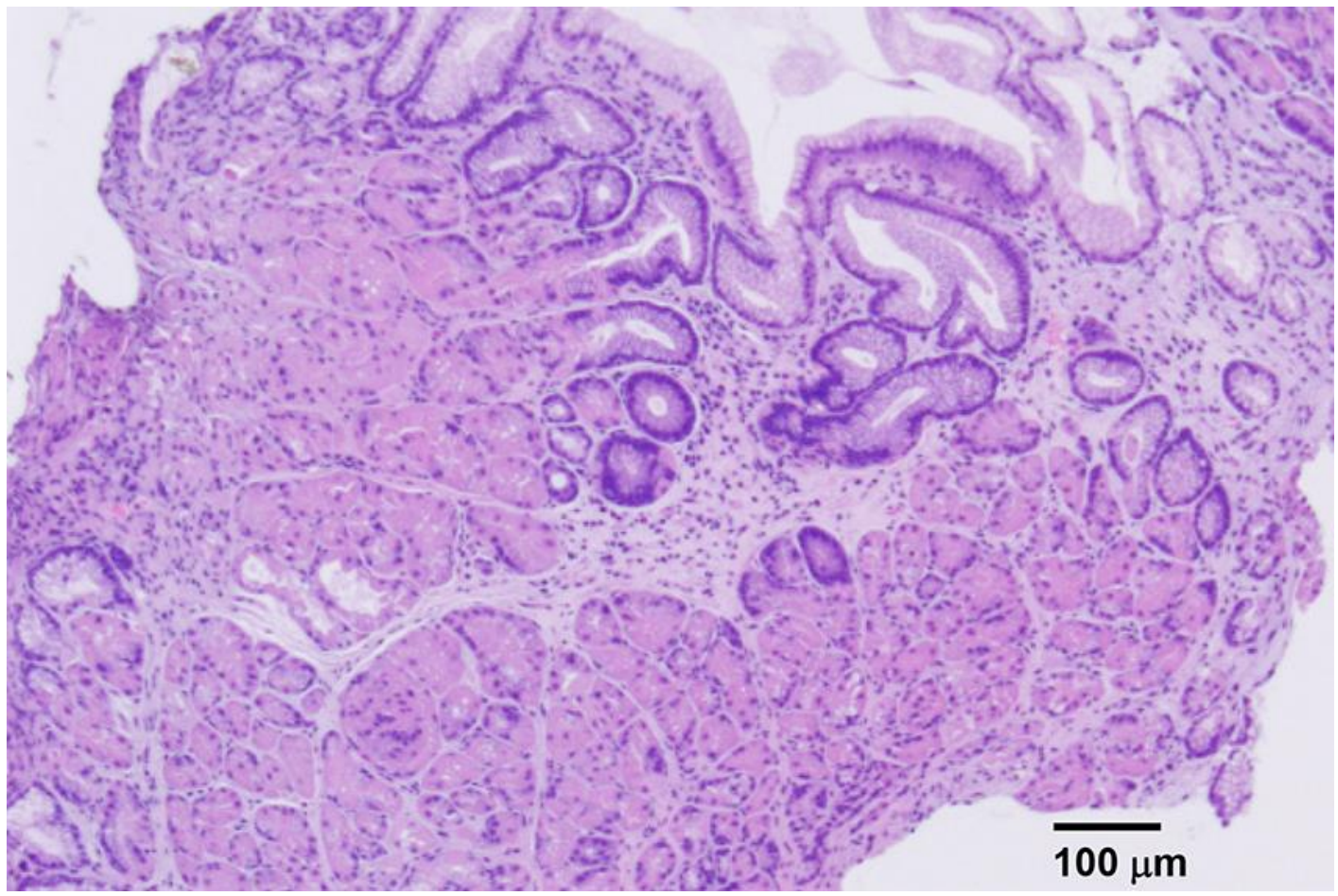

Fig. 3. Pathological findings of gastric polypoid lesions. Pathology revealed hyperplastic polyp without focal dilated cystic glands. 
Case Reports in
Gastroenterology
Case Rep Gastroenterol 2020;14:561-569

(c) 2020 The Author(s). Published by S. Karger AG, Basel www.karger.com/crg

Murata et al.: Cronkhite-Canada Syndrome before Presenting Ectodermal Symptoms

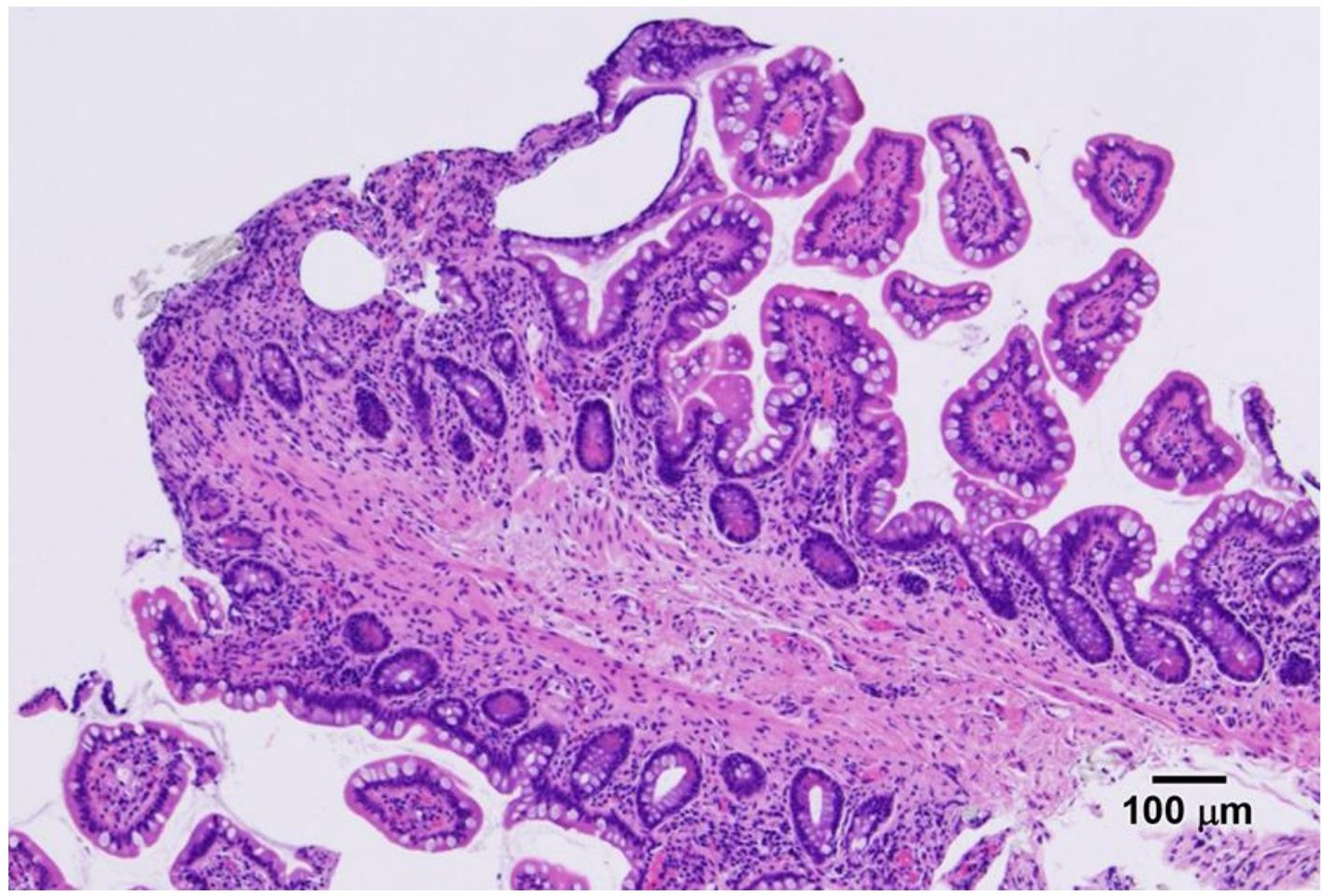

Fig. 4. Pathological findings of polypoid lesions in the terminal ileum. Similar findings to gastric lesions were seen. 


\section{Case Reports in Gastroenterology}

\begin{tabular}{l|l}
\hline Case Rep Gastroenterol 2020;14:561-569 \\
\hline DOI: 10.1159/000510920 & $\begin{array}{l}\text { (c) 2020 The Author(s). Published by S. Karger AG, Basel } \\
\text { www.karger.com/crg }\end{array}$ \\
\hline
\end{tabular}

Murata et al.: Cronkhite-Canada Syndrome before Presenting Ectodermal Symptoms
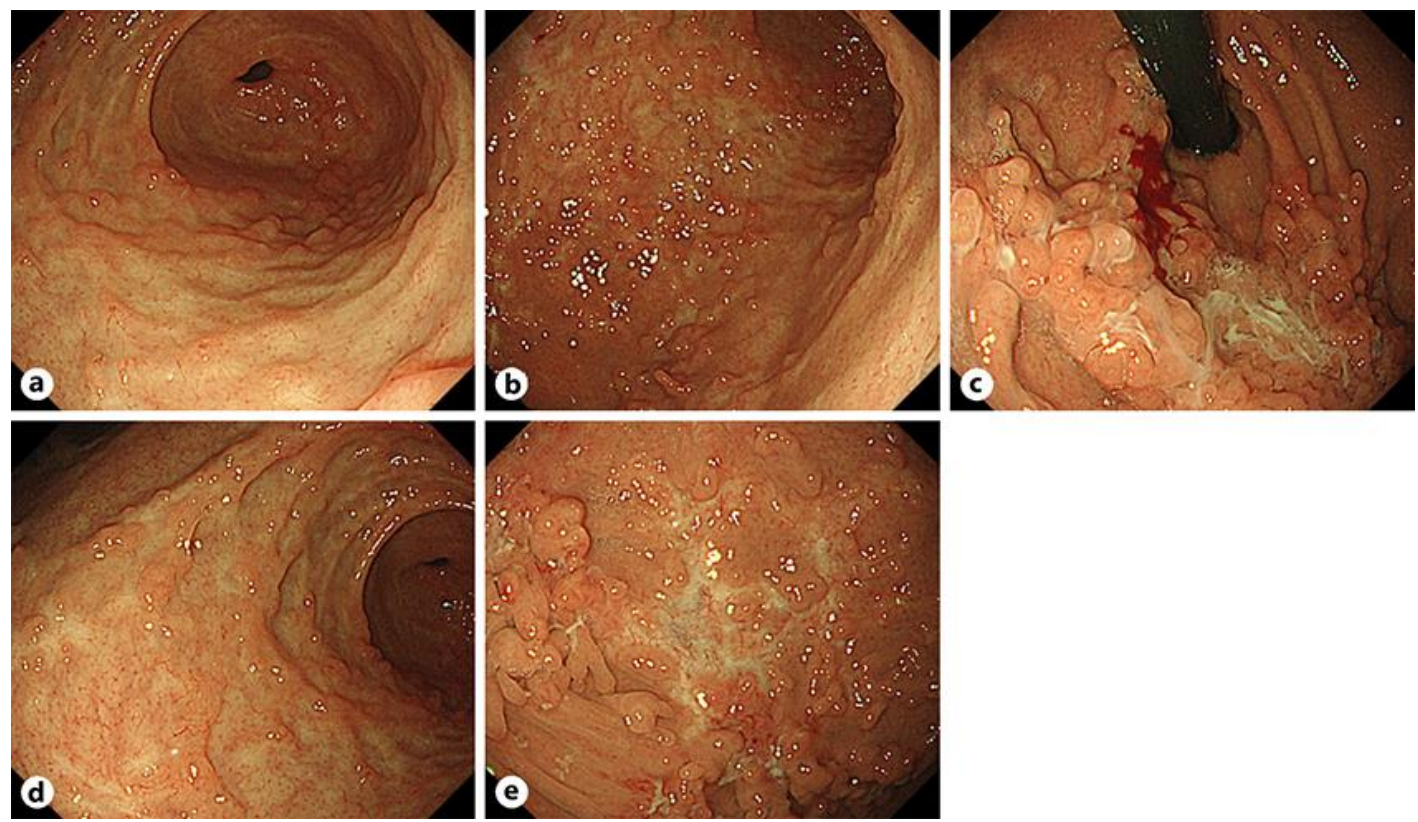

Fig. 5. Esophago-gastro-duodenoscopy 1 year after treatment with corticosteroids. The size and the number of gastric polypoid lesions decreased (a: antrum, b: great curvature, c: cardia, and, $\mathbf{d}$ : anterior wall of the upper part of stomach angle). Some of the polypoid lesions disappeared and showed scar formations (e).

Table 1. Changes in protein synthesis or body weight before and after therapy

\begin{tabular}{llll}
\hline & Before therapy & 1 year after therapy & Normal range \\
\hline Alb & 3.7 & 4.2 & $3.9-4.9 \mathrm{~g} / \mathrm{dL}$ \\
ChE & 254 & 344 & $229-521 \mathrm{IU} / \mathrm{L}$ \\
T-cho & 192 & 248 & $150-219 \mathrm{mg} / \mathrm{dL}$ \\
Body weight & 42.0 & 47.0 & \\
\hline
\end{tabular}

Alb, albumin; ChE, cholinesterase; T-cho, total cholesterol. 